\title{
Observations of the Ushant tidal front in September 2007
}

\author{
A. Le Boyer ${ }^{a}$, G. Cambon ${ }^{\mathrm{a}, 1}$, N. Daniault ${ }^{\mathrm{a}}$, S. Herbette ${ }^{\mathrm{a}}$, B. Le Cann ${ }^{\mathrm{a}}$, L. Marié $^{\mathrm{b},{ }^{*}}$ and P. \\ Morin ${ }^{\mathrm{c}}$
}

\begin{abstract}
a Laboratoire de Physique des Océans, UMR CNRS/IFREMER/IRD/UBO 6523, Université de Bretagne Occidentale, Brest, France

b Laboratoire de Physique des Océans, UMR CNRS/IFREMER/IRD/UBO 6523, IFREMER/Centre de Brest, Plouzané, France

${ }^{c}$ Adaptation et Diversité en Milieu Marin, UMR CNRS/UPMC 7144, Station Biologique, Place Georges Tessier, Roscoff, France

1 Present address: Laboratoire d'Etudes en Géophysique et Océanographie Spatiales, UMR CNES/CNRS/IRD/UPS 5566, 18, avenue Edouard Belin, Toulouse, France.
\end{abstract}

*: Corresponding author : L. Marié, email address : louis.marie@ifremer.fr

\begin{abstract}
:
The Ushant tidal front is the dominant feature of the summer season hydrological structure of the Iroise Sea. It separates tidally mixed coastal waters from thermally stratified open Celtic Sea waters. This article reports on observations made in September 2007 during two short cruises that took place aboard R/V "Côtes de la Manche", and gives a general account of the physical structure of the front along one cross-frontal transect. The data set comprises data from a 4 month ADCP mooring, short CTD/fluorescence/nutrients transects, Lagrangian drifter trajectories, and HF radar surface current measurements. One finding is that the surface and bottom fronts, being affected by different dynamical influences, are not necessarily coincident in the vertical. This entails that the opposite density gradients located above and below the thermocline depth do not necessarily compensate, and can each be associated with a significant surface geostrophic expression. A second finding is that mixing effects bear a very strong influence on the thermal structure of the warm-water intrusions associated with frontal cyclonic eddies of the kind described by Pingree [1978. Cyclonic eddies and cross-frontal mixing. Journal of the Marine Biological Association of the United Kingdom 58 (4), 955-963].
\end{abstract}

Keywords: Shelf dynamics; Tidal mixing front; Hydrology; HF radars; Drifters; Nutrients

\section{Introduction}

The Ushant thermal front (Le Fèvre and Grall, 1970; Pingree et al., 1977;Mariette et al., 1982; Le Corre and Mariette, 1985;Mariette and Le Cann, 1985) is the dominant feature of the summer season hydrological structure of the Iroise Sea (shelf sea to the West of France). It separates tidally mixed coastal waters from thermally stratified open Celtic Sea waters. It is clearly apparent on satellitederived SST maps of the area from the end of May to roughly the end of October as a sharp discontinuity in surface temperature (a situation typical of this period is presented in figure 1). The cross-front length scale and the SST gradient at the front are in the range usually observed on such fronts on the western shelves of Europe (Simpson, 1981) and respectively of the order of a few kilometers and one $\mathrm{C} / \mathrm{km}$.

Such fronts are ubiquitous in shelf seas (Hill et al., 2008). Intensively studied examples are those of the Irish (Horsburgh et al., 2000), Celtic (Brown et al., 2003) and North (Hill et al., 1993; Brown et al., 
2001) seas, as well as the front present on Georges Bank (Garrett and Loder, 1981; Houghton, 2002) on the United States East Coast.

Their existence has been ascribed by Simpson and Hunter (1974), in their seminal article on the Irish Sea fronts, to the interplay of tidally-generated turbulent mixing with the tendency to re-stratification due to surface radiative heating. Based on this hypothesis, the authors derived through energetic balance considerations a criterion for existence of the fronts as the ratio $h / U^{3}$ of the water column height to the cube of the barotropic tidal velocities amplitudes, which proved successful in subsequent studies (Pingree, 1978). Applications of this criterion to the Iroise Sea are discussed in (Mariette and Le Cann, 1985). Dynamical models of shallow sea fronts are discussed in (Garrett and Loder, 1981), with emphasis on the Georges Bank case.

Despite its strong influence on the Iroise Sea ecosystem (Le Fèvre and Grall, 1970; Le Fèvre, 1986), and despite its interest for process studies as a tidal front archetype, the Ushant thermal front seems to have attracted only remote attention from physical oceanographers since the SATIR-DYNATLANT field program of 1982 (Le Corre and Mariette, 1985).

The aim of this article is to provide a description of the Ushant Front structure, notably the along front residual circulation, and of the role of diapycnal mixing in frontal dynamics. The analysis is based on hydrological, Lagrangian drifter, ADCP mooring and HF radar data collected during the summer of 2007.

\section{Hydrology}

\subsection{Data Set}

Figure 1 here

Figure 1 presents a synthetic view of the data set used in this article, which was acquired during two short cruises that took place from September 13th to September 15th and from September 19th to September 22nd 2007 aboard CNRS/INSU R/V "Côtes de la Manche". During both periods the weather was fair, with northerly winds of order $5 \mathrm{~m} . \mathrm{s}^{-1}$ during the first period and south-westerly winds of order $7.5 \mathrm{~m} . \mathrm{s}^{-1}$ during the second period. Tidal amplitudes were different, the first (resp. second) leg taking place during a spring (resp. neap) tide period. The first leg was devoted to the recovery of an ADCP mooring previously deployed on June 6th, 2007, to the deployment of Lagrangian drifters (5 Technocean SVP-GPS drifters, holey-sock drogued at 50 and $15 \mathrm{~m}$ depth, and 4 Technocean SVP-GPS drifters with surface CODE-type drogues), and to four CTD transects comprising 55 stations marked as black dots in figure 1. During the second leg, three transects comprising another 55 stations marked as red dots in Figure 1 were surveyed. As will be discussed in section 6 below, the extremely large tidal excursion encountered in the area makes synopticity assumptions very questionable even over the time span of one single transect. This article will thus focus primarily on the $48^{\circ} 08^{\prime} \mathrm{N}$ transect (second southern-most black dots line in figure 1), and other transects will only be mentioned as side information where relevant. 
CTD/fluorescence measurements were performed during the cruises using an SBE25 CTD and a Chelsea Aqua-Tracka Mk III Fluorometer. Post-cruise calibration showed the temperature sensor offset to be of the order of $-0.001{ }^{\circ} \mathrm{C}$. At least two salinity samples were taken per station, one at the top and one at the bottom of the water column, and were processed within less than a week using a Guildline Portasal salinometer kept in a controlled environment. Salinometer calibration using OSIL standard seawater shows that the expected accuracy for these samples is better than $\pm 5 \times 10^{-3}$ psu. Thermal inertia effects (Lueck, 1990; Lueck and Picklo, 1990) induce large errors in salinity estimates using the conductivity measurements, which tend to overwhelm the extremely small salinity contrasts actually encountered in the area (see section 2.7). The samples values are thus the only reliable salinity estimates available at the time of writing.

Conversion of the raw fluorescence counts to chlorophyll-a concentrations was performed using precruise calibration data only (i.e. calibration with respect to samples concentration values has not been performed).

Nutrients and chlorophyll were sampled at roughly half of the stations. Nutrient concentrations were determined in surface and bottom waters using a Bran and Luebbe AutoAnalyser II according to classical methods (Aminot and Chaussepied, 1983), and following the procedures described in (Treguer and Le Corre, 1975). Analytical precisions were respectively $\pm 0.1 \mu$ mol. $1^{-1}$ for nitrate and silicate, $\pm 0.02 \mu \mathrm{mol}^{-1^{-1}}$ for phosphate and $\pm 0.01 \mu$ mol. $1^{-1}$ for nitrite.

Evidence of internal wave activity was apparent at a few stations, the profiles measured by the CTD during downcast and upcast being vertically shifted with respect to one another. The data set is however clearly not sufficient to permit study of these effects per se, and they will not be mentioned further.

\subsection{Temperature section along the $48^{\circ} 08^{\prime} \mathrm{N}$ transect}

Figure 2 here

Figure 2 presents the in-situ temperature section along the $48^{\circ} 08^{\prime} \mathrm{N}$ transect. One striking feature is that the transect indeed crossed the bottom front, while the satellite SST map seems to indicate it missed the surface front. The temperature at the eastern-most station, presented below in figure $4 \mathrm{c}$, is roughly uniform in the water column, and has values consistent with those observed during the transect surveyed closer to the shore during the second leg. The situation at the surface is quite confusing, with surface temperatures reaching their maximum value of roughly $16^{\circ} \mathrm{C}$ at the intermediate longitude of $5^{\circ} 23^{\prime} \mathrm{W}$ and not at the western end of the transect. An interesting point is that the thermocline shallows where the surface temperature reaches its maximum, and is comparably deeper on the sides. A possible interpretation of this will be discussed in section 6.

Regardless of any doubt concerning the synopticity assumption, these remarks indicate that the bottom and surface fronts are not necessarily coincident, and actually seem to have a considerable degree of independence with respect to one another. An immediate corollary is that the opposing geostrophic velocities 
associated through the thermal wind relation with the bottom and surface density gradients do not necessarily interfere destructively. At this point, a first conclusion is that it is possible in a tidal front region to have quite swift geostrophic velocities directed in opposite directions above the two (bottom and surface) fronts, instead of one single zone of sluggish velocities at middepth due to the destructive interaction of two opposite and co-located density gradients. Recognition of the important role of bottom fronts as structuring elements of the circulation in shelf seas has recently emerged (Hill et al., 2008).

\title{
2.3. Geostrophic velocities estimates
}

Figure 3 here

Figure 3 presents the northward geostrophic velocities estimated across the transect, under the assumptions that the geostrophic velocity is zero at the bottom, that the salinity has negligible influence on the density, and that diffusive effects can be neglected outside of the bottom boundary layer. The first assumption, considered by (Hill, 1996) in his study of the dynamics of shelf seas "Cold Pools", is based on the idea that Ekman transport convergence/divergence in the bottom boundary layer introduces a negative feedback on the currents close to the bottom, by rising or lowering the sea surface. Its validity is hard to assess quantitatively, but it was used with good qualitative success in several studies of the Irish Sea Cold Pool (Horsburgh et al., 2000; Brown et al., 2003; Hill et al., 2008). The second assumption finds quantitative support in the very slight range of variation of the samples salinity values presented in figure 7, which prove that temperature variations have an overwhelming influence on the density structure of the area. At any rate, the neglect of salinity variations can be expected to be a very minor approximation compared to the neglect of turbulent diffusion of momentum. The last assumption is probably the most questionable, as the estimated geostrophic surface velocities are indeed very swift $(O(30 \mathrm{~cm} / \mathrm{s})$ above the bottom front).

The overall pattern of estimated velocities is essentially consistent with the intuition developed at the end of the previous section. The velocities are consistently directed northward, as expected from the overall westward increase of density near the bottom. Over the bottom front, sharp temperature gradients $\left(1{ }^{\circ} \mathrm{C}\right.$ temperature contrast in less than two nautical miles) and steep isotherms (the $13.5^{\circ} \mathrm{C}$ isotherm dips $50 \mathrm{~m}$ between stations 14 and 15) are associated with swift northward velocities. A second patch of northward velocities is visible at middepth westward of $5^{\circ} 25^{\prime} \mathrm{W}$, which indicates that the continuous bottom temperature decrease towards the center of the Celtic Sea "cold pool" (see figure 7) might also contain a series of small front-like structures.

The situation on the western half of the section is complicated by the presence of a meander in the surface front, clearly visible on the SST map of figure 1. There, the hump in the thermocline apparent in figure 2 transposes to an estimated cyclonic circulation in the surface layer. These features will be the subject of a focused analysis in section 6 .

\subsection{Selected temperature profiles}

\author{
Figure 4 here
}


Figure 4 presents temperature profiles representative of the different areas encountered during the $48^{\circ} 08^{\prime} \mathrm{N}$ transect. In figure $4 \mathrm{a}$, the transect approaches from the west the warm meander in the front visible in the SST map of figure 1. The lower parts of the profiles thus sample the cold pool located seawards from the bottom front, while the upper parts cross the surface front, progressing into the core of the meander. A noteworthy feature is that the surface temperature rises progressively, but that the thermocline seems to sharpen and rise in the process. This behaviour will be discussed in section 6 .

Figure $4 \mathrm{~b}$ is much messier. At the surface, the transect leaves the warm meander, and thus crosses the surface front shorewards. At the bottom, the transect approaches the bottom front from its seawards side. The first profile (lightest grey) resembles quite closely those of the previous inset. The second profile has roughly the same surface temperature, but below the surface layer temperature decreases almost linearly with depth until the bottom layer is reached. The third profile displays the same linear decrease of temperature with depth, but the surface layer temperature is about one degree less. The fourth and fifth profiles follow, in which the linear decrease is replaced by a very thick homogeneous surface layers, reaching roughly 30 meters depth. A sixth profile has the same linear temperature gradient between the surface and bottom layers as the second and third. In all these profiles, the bottom layer temperature is roughly the same and close to $12.75^{\circ} \mathrm{C}$.

Figure $4 \mathrm{c}$ is more straightforward, and displays the temperature profiles behaviour across the bottom front. In the first (lightest grey) profile, the surface layer is quite deep, and is followed by a gentle, linear, temperature gradient until a still quite thick bottom layer is reached. The surface mixed layer thickness increases slowly, and the temperature there remains roughly constant. Below the mixed layer, the temperature varies roughly linearly with depth, with a weakening slope. The profile then enters the bottom mixed layer, over which the temperature is vertically uniform. The bottom layer temperature increases quite rapidly from one profile to the next, as shown below in figure 7. The last profile, obtained shorewards from the bottom front, is rather uniform and $0.2^{\circ} \mathrm{C}$ warmer than the others. A gentle slope in the temperature profile, whose origin is hard to explain in the absence of shorewards data, is however apparent.

\subsection{Selected chlorophyll-a concentration profiles}

Figure 5 here

Figure 5 now presents the raw (i.e. not calibrated with respect to the collected in situ samples) chlorophyll-a profiles acquired at the same stations.

As explained above, the profiles shown in figure 5a sample the surface layer seawards of the bottom front, while the transect approaches the surface front meander from the west.

The profiles in this area have a straightforward behaviour in that high chlorophyll-a concentrations remain trapped in the surface layer. The concentrations in the surface layer are high and quite uniform for the first profiles, but progressively decrease and grow a peak at the thermocline level as it shallows. This peak is well documented (Pingree et al., 1977; Holligan, 1981), though its origin remains a subject 
of controversy. Hypotheses put forward by Le Fèvre (1986) include the concentration by the jump in density at thermocline level of sedimenting organisms produced in the surface layer, or the advection by the transverse circulation associated to the frontal structure (Garrett and Loder, 1981; Le Fèvre, 1986) of material produced at a different location. More recently, Sharples et al. (2001) have proposed it to be associated to the slow diffusion of nutrients from the bottom layer into the base of the base of the thermocline through turbulent diapycnal mixing.

As in the case of the temperature profiles, the chlorophyll-a concentration profiles leaving the meander display a considerably more complicated behaviour, starting with a shallow layer with modest concentrations, bounded below by a sharp peak, then displaying a much deeper penetration below the thermocline, with again roughly linear dependence with depth, then one profile with high surface values and no peak. The last three profiles have roughly similar shapes, but are associated with decreasing surface values. In all cases, a slow, blunt decrease from the surface values is followed at 30 meters depth by a uniform plateau to the bottom.

Finally, the concentration profiles in the bottom front area (figure 5c) are all fairly uniform with depth, as expected in such a well-mixed area, and the differences between them are essentially within the error bar of the uncalibrated measurements.

\subsection{Nutrients along the $48^{\circ} 08^{\prime} \mathrm{N}$ transect}

\section{Figure 6 here}

Figure 6 presents the nutrient (phosphate, silicate, nitrate, nitrite) surface and bottom concentrations along the $48^{\circ} 08^{\prime} \mathrm{N}$ transect, superimposed on the chlorophyll-a concentration section. Vertical distributions are similar to those usually observed in tidal fronts (Simpson and Hunter, 1974; Pingree et al., 1977; Pingree, 1978; Holligan, 1981; Morin et al., 1985, 1993). Maximum nutrient concentrations are observed in the cold pool bottom waters below the thermocline in the western part of the section. Nitrate and phosphate concentrations are low in the warm surface waters and nearly exhausted (respectively $<0.4 \mu$ mol. $1^{-1}$ and $<0.10 \mu \mathrm{mol}^{-\mathrm{l}^{-1}}$ ) in the core of the meander, suggesting a possible nutrient limitation of primary production, whereas silicate concentrations remain relatively high $\left(>1.5 \mu\right.$ mol. $\left.1^{-1}\right)$ with no significant variations in the upper stratified waters along the section. The chlorophyll maximum at the thermocline level in the core of the meander is vertically reduced (see figure 5). This station coincides with the warm and nutrient-poor waters whose origin are the surface waters of the stratified side of the frontal area where nutrient have been assimilated by phytoplankton during spring and summer and not significantly re-enriched by vertical inputs from the cold pool waters through the thermocline. Chlorophyll maxima $\left(>0.8 \mu \mathrm{g} . \mathrm{l}^{-1}\right)$ are more developped on both sides of the meander (see also figure 5) where nutrient concentrations, light levels and vertical stability are more favourable for phytoplankton development. Chlorophyll concentrations are reduced in the well-mixed area $\left(<0.4 \mu \mathrm{g} \cdot 1^{-1}\right)$ where nutrient surface concentrations are not limiting for the phytoplankton development. In this area the entire water column is vertically mixed by the tidal currents 
and phytoplankton is entrained out of the euphotic zone and permanently exposed to different light levels during a major part of the day. Despite favourable nutrient conditions, phytoplankton development is lightlimited and chlorophyll concentrations remain low in the well-mixed area.

\subsection{Salinity distribution}

\section{Figure 7 here}

Figure 7 presents plots as a function of longitude of the observed surface and bottom temperatures and sample salinities in the data set obtained during the four transects of the first leg. The pattern for the temperatures is quite clear: at the western end of the transects, bottom and surface temperatures are well separated, showing a significant stratification is present. While moving eastward, one observes a high in surface temperatures at the crossing of the front meander (around $5^{\circ} 25^{\prime} \mathrm{W}$ ), while the bottom temperatures follow a well-defined curve, and slowly increase. At the eastern end, the bottom temperatures increase more rapidly, and finally join the surface temperatures curve, in the homogeneous zone.

The salinity distribution, though equally well defined, is much harder to interpret, and an explanation will certainly require more experimental data. Again the bottom values follow a well-defined, steadily increasing eastwards curve. The lowest surface salinities are found at the western ends of the transects, where they display more scatter. In fact, the very highest salinities, above $35.45 \mathrm{psu}$, are observed in the well-mixed region at the eastern end of the transects, i.e. in the area presumably most exposed to freshwater influence from the coast, while the open-sea area, which one would expect to be most exposed to open ocean influence, presents the lowest salinity values. Such a situation was also observed at the end of summer during at least part of the 1982 SATIR-DYNATLANT cruise (Le Corre and Mariette, 1985), as well as during a SeaSoar survey conducted in 2005 by SHOM, the French hydrographic institution (Y. Morel, pers. comm.). Early summer salinity sections presented in (Holligan, 1981) show a different pattern, with rather uniform, and low, salinities observed on a transect located slightly north of ours.

\section{Mooring data}

Figure 8 here

This section presents the velocity measurements collected by an RDI $300 \mathrm{kHz}$ ADCP moored in the area from June 6th to September 13th 2007. HF radar data (see section 5 below) suggest that the surface northward jet associated with the bottom front exhibited little variability during the summer of 2007 , so the instrument can be thought to have spent most of the deployment period in the seawards "cold pool", where it was found at recovery. The surface front, conversely, is seen in the satellite SST maps to display a very high level of variability over time scales of a few days. This makes chasing glimpses of its signature in the overwhelming tidal signal a very difficult undertaking. This section will thus mainly focus on the tidal 
properties and on the time-averaged flow over the deployment period, and leave more refined analysis of the data for future work.

The tide in the area is strongly dominated by the M2 and S2 components, though the influence of other components such as M4 is clearly visible in the velocity signal. Figure 8a presents tidal ellipses computed using the $t_{-} t i d e$ software package described in (Pawlowicz et al., 2002). The M2 barotropic tide ellipse semi-major axis is $56 \mathrm{~cm} / \mathrm{s}$, pointing to $28^{\circ}$, and the semi-minor axis is $14 \mathrm{~cm} / \mathrm{s}$. The $\mathrm{S} 2$ barotropic tide ellipse semi-major axis is $20 \mathrm{~cm} / \mathrm{s}$, pointing to $28^{\circ}$, and the semi-minor axis is $4 \mathrm{~cm} / \mathrm{s}$. The two ellipses having nearly identical orientations, it is easy to compose the two tidal components, and obtain maximal spring tides amplitudes of order $76 \mathrm{~cm} / \mathrm{s}$. It is also clear from that graph that the tidal signal amplitude is overwhelming with respect to the time-averaged component of the velocity signal. The tidal components amplitudes and phases vary somewhat with $z$, with minimal amplitudes near the bottom, growing slowly to reach maximal amplitudes at thermocline level, then decreasing slightly to the top of the measurement range. The bottom M2 tidal currents lead the thermocline level currents by roughly half an hour. The phases remain roughly constant above thermocline level.

The time-averaged velocity profile at the deployment point is presented on the polar diagram of figure $8 \mathrm{~b}$, and as a function of depth in figure 9. On both graphs of figure 9, the rms amplitudes of the tide-filtered velocity signal have also been represented. This component displays a much more important dependence with $z$. It points south-eastward at the bottom of the water column, then veers to the north-east direction at thermocline level, then back to the original direction with a somewhat higher amplitude. The velocities are essentially of the order of magnitude of the geostrophic estimates of section 2 , but the profiles clearly show the assumption of zero tide-filtered currents at the bottom to be questionable.

Figure 9 here

It is difficult to draw a definite explanation for the structure of the time-averaged flow component, as many distinct forcing mechanisms can be expected to play a role. Geostrophic equilibrium could for instance explain the maximum signal amplitude at thermocline level, but then one would expect the induced flow to be more north-southerly aligned. Tidal forcing through nonlinear self-interaction could explain the fact that the direction of permanent flow is nearly aligned with that of the tidal ellipses. The effect of surface wind forcing could possibly be responsible for the z-independent component of the mean flow. In any event, a careful analysis of the dynamical balance of the flow at the mooring position is necessary before firm conclusions can be drawn. As a first step, insight into the dynamics of the turbulent diffusivity of momentum could be gained from a careful analysis of the $z$-dependence of the tidal components amplitudes and phases.

\section{Lagrangian velocities}

Figure 10 here 
Figure 10 presents the trajectories of the Lagrangian drifters deployed during the cruise first leg. This section mainly focuses on the $15 \mathrm{~m}$ holey-sock drogued drifter trajectories shown in figure 10a, as they provide a consistent, homogeneous dataset.

A first remark is once more that the tidal signal influence is extremely strongly visible in the trajectories. Analyzing with t_tide the motion of the buoy positions barycenter yields a tidal excursion ellipse major axis of order $5.7 \mathrm{~km}$. As mentioned in earlier sections, this casts doubt on the synopticity of the hydrology transects, but at the same time provides input for a tentative attempt to correct these effects discussed below in section 6, by instrumenting the motion of water masses in the area.

A second remark is that the drifter trajectories come in strong support of the ideas about surface currents developed in section 2.2 above. The two drifters launched east of $5^{\circ} 20^{\prime} \mathrm{W}$ both made very rapid northward progress (fits to the time-latitude data over the first three days indicate northward drift at roughly $18 \mathrm{~cm} / \mathrm{s}$ ) along the 100 meters isobath, roughly where the geostrophic estimates of section 2 predicted a strong surface current associated to the bottom front. Conversely, the western-most $15 \mathrm{~m}$ drifter moved quite swiftly south-eastward, as did the surface drifter launched at the same position. Though its deployment position might seem closer to the bottom front signature, the $50 \mathrm{~m}$ drifter followed the same south-eastward course as these two buoys. The conditions at the time of deployment however clearly indicated the presence of very warm $\left(\sim 16.9^{\circ} \mathrm{C}\right)$ surface waters, which implies it was definitely launched in the surface front area.

The two northward-going drifters soon reached the zone of strong influence of the Island of Ushant, around which they performed characteristic anti-cyclonic looping motion. This pattern of motion is frequently observed in drifter trajectories in the vicinity of islands (Pingree and Mardell, 1987).

One of the drifters exited the Ushant Archipelago to the north-east, and started a slow north-eastward drift into the English Channel, superimposed on rectilinear, very large tidal excursions. This pattern is frequently observed in drifter trajectories in the area (Y. Morel, pers. comm.). The other drifter drifted after a while to the south-west, and rejoined the northward jet from the shorewards side. After a small loop, it drifted to the south-east. The rest of its trajectory (not shown) carried it past the "Raz de Sein", and finally westward to the shelf break.

The CODE-type surface drifters, whose trajectories are presented in figure 10b, are more exposed to the influence of wind-induced surface currents, and to the influence of Stokes drift due to surface waves. Both these influences were however small at the time of deployment, and the same overall pattern of motion can be recognized, at least at the beginning of trajectories. The two eastern drifters rapidly moved northward, and started making incursions in and out of the Ushant Archipelago, on which one actually crashed. The other one exited the Archipelago to the north-east, and went very close to the coast. At this point, pushed by strong northerly winds, it dashed to the south, passed the "Raz de Sein". It then moved again northwestward, almost back to its deployment point. There it started a second time northward. During the rest of its trajectory (not shown), it spent much time without making much progress at the north-west of Ushant, then exited the area to the north-east and followed the coast along the same pattern as the $15 \mathrm{~m}$ drogued 
drifter mentioned above. The two western drifters started by drifting to the southeast along the surface front. The southernmost one continued south-eastward in very much the same way as one of the $15 \mathrm{~m}$ drogued drifters. The other one remained trapped for some time between the south-eastward flow and the northward jet associated with the bottom front. It finally (not shown) started to move northward, spent some time in the Ushant Archipelago, then left the area due north.

\section{HF Radar Data}

Figure 11 here

Figure 11a presents a snapshot of the tide-filtered surface currents measured using an HF radar system (WERA system (Gurgel et al., 1999b,a)). This system, which is operated by SHOM, provides at 20 minutes interval synoptic observations of surface currents in the area. Its accuracy has been checked by SHOM through comparison with surface drifters velocities and over 7 months of ADCP current measurements (Cochin, 2006). The surface currents values estimated by the different instruments were usually found to be less than $15 \mathrm{~cm} / \mathrm{s}$ apart from each other, which is essentially the conclusion one reaches when comparing the data with the ADCP measurements presented above. In fact, it seems the uncertainty may actually reside not so much in the instruments themselves as in the definition of what one means by "surface velocity" (sensitivity of the measuring technique to shear in the eulerian current, to Stokes drift, to the sea state, etc...).

The $15 \mathrm{~cm} / \mathrm{s}$ uncertainty is amply sufficient for operational purposes, given the intense tidal signal dominating currents over the area, but is essentially the order of magnitude of the longer-period currents which are the focus of this article. Nevertheless, figure 11a shows a clear northward surface jet around $5^{\circ} 10^{\prime} \mathrm{W}$, consistent with the position estimated in figure 3 for the geostrophic surface current associated to the bottom front. A broad southward flow is apparent to the west of the SST front, as is the influence of the front meander on the surface velocities. The image is synoptic with the $48^{\circ} 08^{\prime} \mathrm{N}$ CTD transect discussed in section 2 .

Observation of the tide-filtered surface currents shows a strong influence of wind, either directly or indirectly through the influence of surface waves (Broche et al., 1983). A focused study is in progress regarding this aspect. Whenever this influence dissipates, however, the signature present in figure 11a reappears. To further evidence the fact that it is a robust and permanent feature of the circulation of the summer of 2007, the time-average of the raw data over the period running from August 15th to September 15th has been presented in figure 11b. Once again, a northward jet above the $100 \mathrm{~m}$ isobath is apparent, as is a broad pattern of southward circulation in the western area. 


\section{Discussion}

In this section two effects are discussed which, though of secondary relevance at first sight, must be carefully considered in the interpretation of the above data.

\subsection{Non-synopticity}

$$
\text { Figure } 12 \text { here }
$$

Figure 12a presents an attempt to estimate the effect of tidal motion on the water particles whose properties were measured during the $48^{\circ} 08^{\prime} \mathrm{N}$ transect. The positions of the water parcels sampled during the stations at the instant our "master" satellite SST map was shot have been estimated using the movement of the drifter "cloud" barycenter (red dots) and the surface currents measured by the HF-radar system (blue dots). This is only a first-order attempt, in that only the mean motion of the drifters cloud (resp the spatial average of the surface currents) was used, and the information regarding the cloud deformation was not used. Both methods give qualitatively similar results, though differences can be seen in the amplitude of the water parcels displacements and most notably in their average meridional drift. It is however easily seen that the effect of the tidal excursion is very strong, and for instance that the warm meander in the front actually moved under the ship track in the course of the transect. This explains why its signature is so large in figures 2, 3 and 4, while the transect had apparently not crossed it. Paradoxically, the water sampled during the southern-most transect, where its effect should have been most apparent, came almost entirely from the area to the north (see figure 12b), and is essentially unaffected by it. This shows that any conclusion drawn from hydrological data in an area of energetic tidal conditions must be carefully checked to withstand even very severe non-synopticity effects. A corollary is that Lagrangian drifters constitute a vital component of any field experiment conducted in such an area. As figure 12 shows, use of HF-radar surface current measurements can be an interesting alternative if available. Care must however be exercised in periods of strong wind and waves activity, when Stokes drift becomes an important contribution to the radar measurements (Broche et al., 1983).

\subsection{Effects of mixing on the structure of a cross-frontal eddy}

Figure 13 here

Frontal eddies are a generic feature of shallow-sea fronts. Using satellite radiometry images, (Pingree, 1978) was the first to provide a survey of the surface expressions of such structures, presenting examples from most of the fronts of the western european shelves, including the Ushant tidal front. According to the author, most of these structures are cyclonic. Their typical scale is of the order of a few tens of kilometers, and their typical lifetime is of the order of a few days. They appear on SST maps as pairs of "hook-like" distortions of the fronts, one warm anticyclonic and one cold cyclonic meander. 
The SST map of figure 1 shows a striking similarity with those presented in (Pingree, 1978). Figure 13 presents a sketch of the surface circulation in the vicinity of the meander sampled by the $48^{\circ} 08^{\prime} \mathrm{N}$ CTD transect mentioned in this study, showing the cyclonic component inferred from (Pingree, 1978). It is quite clear that the CTD transect actually sampled the warm anomaly induced in the front by the cyclonic motion, and unfortunately stopped mid-way across the cold anomaly.

Partial though it may be, this transect is interesting in that it displays non-trivial differences between the thermal structure observed and that inferred, using surface information alone, by (Pingree, 1978).

Figure 14 here

Figure 14 presents a sketch of the structure proposed by (Pingree, 1978). Clearly, as one gets closer to the meander core the temperature profiles progressively sample warmer surface layers, but the warm water layer thickens, which is the opposite of the observed behaviour. The meander sampled by the $48^{\circ} 08^{\prime} \mathrm{N}$ transect is thus not satisfactorily described by this "adiabatic" model.

Figure 15 here

An alternative cartoon which is more consistent with the observed temperature profiles is presented in figure 15. Going outwards from the core of this meander, one observes a mixed layer temperature decrease, compensated by a thickening of the homogeneous layer of warm water. Finally, a distance away from the meander, the thermocline level and mixed layer temperature return to their normal values. Returning to the temperature section of figure 2 with this structure in mind, one interprets the shape of the thermocline observed between stations 1 and 10 as the reflect, not of a hump around stations 4, 5 and 6, but of a circular dip surrounding the warm intrusion, and crossing the CTD transect at the locations of stations 1 and 2 and of stations 8,9 and 10 .

This dip in thermocline level on the periphery of the warm intrusion can likely be ascribed to the consumption of cold water by vertical mixing, and the subsequent volume increase of the mixed water present in the surface layer, whereas a possible explanation for the differences in mixing efficiency is the stabilizing effect of the increased density difference across the thermocline under the warm anomaly.

The transect at $48^{\circ} 07^{\prime} \mathrm{N}$, which due to the tidal motion sampled more northern waters, and in which the influence of the meander is smaller, supports this view, in that the thermocline remains consistently at a shallower level. The temperature section along this transect is shown in figure 16b. Further support also comes from the first chlorophyll-a concentration profiles of figure $5 \mathrm{a}$ and from figure 6 , which show rather high concentrations of nutrients and high levels of primary productivity evenly distributed in the surface layer on both sides of the meander. Both these features can be considered indicative of recent injection of nutrients, hence of recent mixing activity.

Figure 16 here 
An additional remark is that the modifications of the density structure of the front effected by mixing tend to affect the velocity structure as well. Besides its direct role in the transport of momentum, mixing can thus be expected to also play an important indirect dynamical role through its influence on the density structure.

\section{Conclusions, Directions for future work}

The observations reported here prove that a mechanism exists by which subtidal currents of measurable amplitude can be generated in the Iroise Sea during the summer, due to the position mismatch of the important density gradients associated with the bottom and surface front. HF radar data show that the northward surface jet associated with the bottom front displayed little variability during the summer of 2007. The HF radars are presently accumulating a data base which will permit the study of its interannual variability. The satellite SST data base, in contrast, shows that the surface front exhibits an extremely high level of variability on time scales of days. Among possible sources of variability, the effects of wind forcing and of varying tidal amplitudes, as well as the effect of the intrinsic instabilities leading for instance to the formation of cyclonic eddies, must be mentioned. Progress is at present impaired in the study of the front dynamics by the difficulty of finding a dynamical framework capable of reliably accommodating the complex effects of mixing.

An interesting outcome of this study is that the oppositely-directed surface flows associated with the two fronts form a region in which fluid particles are strongly sheared and move slowly. It is actually plausible that a closed re-circulation cell might form. The residence time of tracers (pollutants, nutrients, organisms) in such areas is known to be very widely distributed, and the impact on biology of the flow characteristics evidenced in this study remains to be assessed. It is for instance clear from the collected Lagrangian trajectories that it is possible for marked particles to remain trapped for times of the order of a few weeks in the area.

A number of questions have been raised in the text concerning the forcing mechanisms responsible for the existence of a variety of dynamical features, among which we find the vertical structure of timeaveraged flow, and the interplay between mixing and geostrophic currents in the region of the surface front. Further FroMVar cruises are planned during the autumns of 2008 and 2009, during which larger-scale, higher-resolution hydrological surveys using a towed undulating CTD as well as direct turbulence intensity measurements using an ad hoc microstructure profiler will be conducted.

\section{Acknowledgements}

It is a pleasure to thank here Stéphane Leizour and Xavier André for their help during the cruises, Thierry Cariou for the analysis of nutrient samples, and Fabrice Ardhuin, Franck Dumas and Heloïse Muller for fruitful discussion during the cruises preparation and subsequent data analysis, and for sharing 
their as yet not published datasets. The help of both crews of R/V "Côtes de la Manche" is gratefully acknowledged, as well as the interest of Anne-Marie Tréguier. Jean-Luc Quéméneur has been an invaluable source of first-hand information on fishing practice in the Iroise Sea. This work is supported by CNRS through an INSU/LEFE/IDAO grant. 


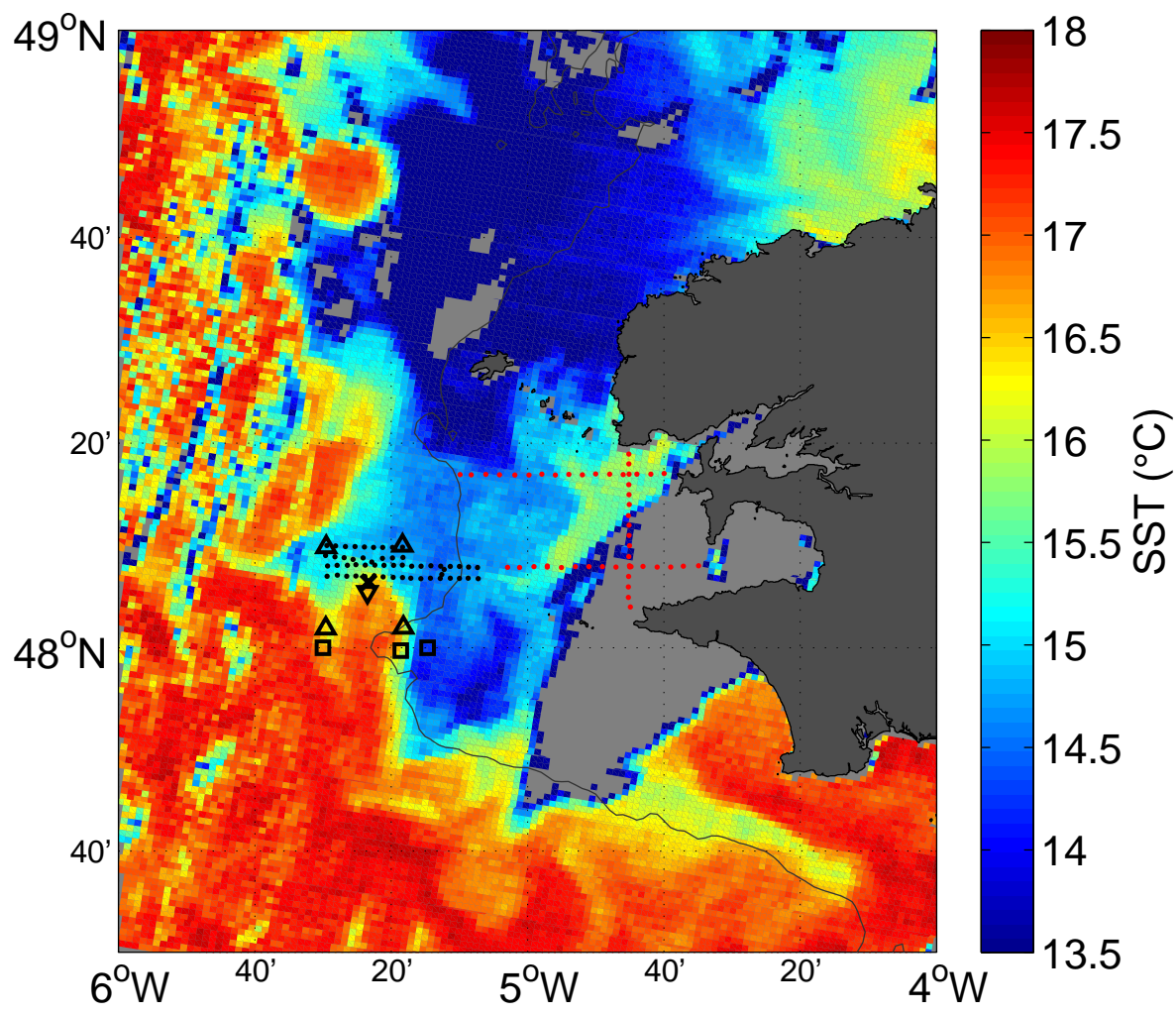

Figure 1: Map of the Iroise Sea, superimposed on the MODIS-derived 4 $\mu \mathrm{m}-\mathrm{SST}$ map for September 14th, 02:20 UTC (Feldman and McClain, 2008). Clouds appear as gray patches and as clutter on the north-western part of the image. The thin black line is the 100 $\mathrm{m}$ isobath. Black (resp. red) dots denote the positions of stations occupied during the 09/13 to 09/15 (resp. 09/19 to 09/22) leg. The black $(\times)$ at $\left(48^{\circ} 6.44^{\prime} \mathrm{N}, 5^{\circ} 23.31^{\prime} \mathrm{W}\right)$ marks the position of the ADCP mooring deployed from June 6th, 2007 to September 13th, 2007. The black $(\nabla, \square, \Delta)$ denote the deployment positions of the respectively $50 \mathrm{~m}-, 15 \mathrm{~m}$-, and surface- drogued Lagrangian drifters. The warm meander frequently mentioned in the text is visible as a $\cap$-shaped intrusion of warm surface waters whose tip is roughly at the mooring location. 


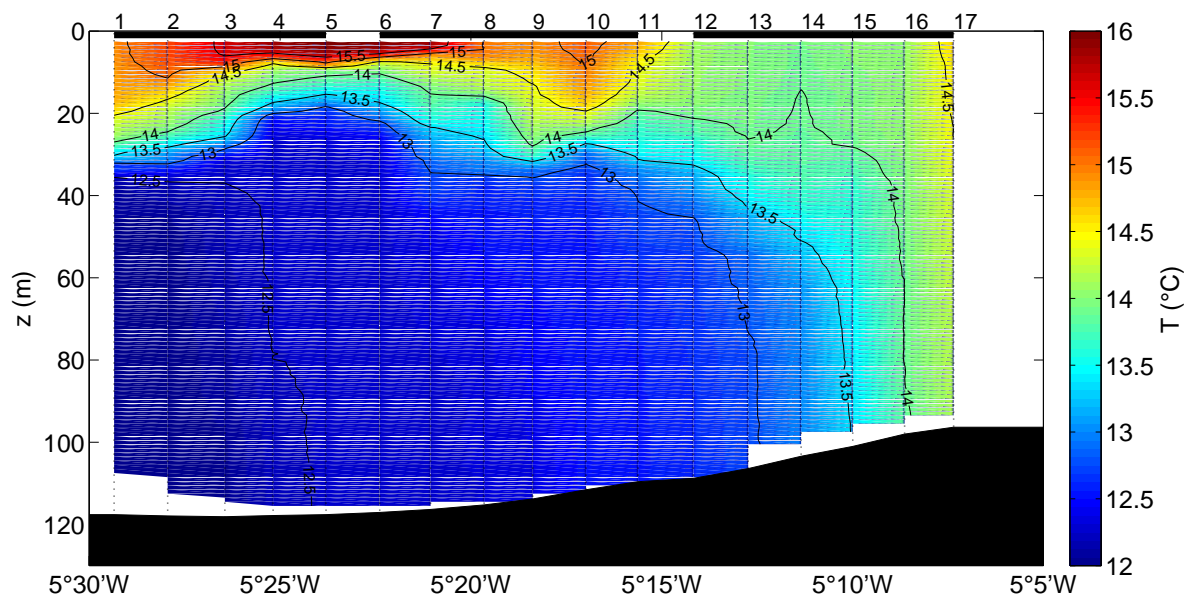

Figure 2: In-situ temperature section along the $48^{\circ} 08^{\prime} \mathrm{N}$ transect. This transect comprises 17 stations, marked on the graph as vertical dotted lines. The distance between station is of the order of one nautical mile. The survey started on 09/14, 01:20 UTC at the westernmost station and ended on 08:05 UTC the same day. The satellite SST map presented in figure 1 is coincident with station number 3 . The three thick black overbars on top of the section mark the groups of stations presented below in figures 4 and $5 \mathrm{a}, \mathrm{b}$ and $\mathrm{c}$. 


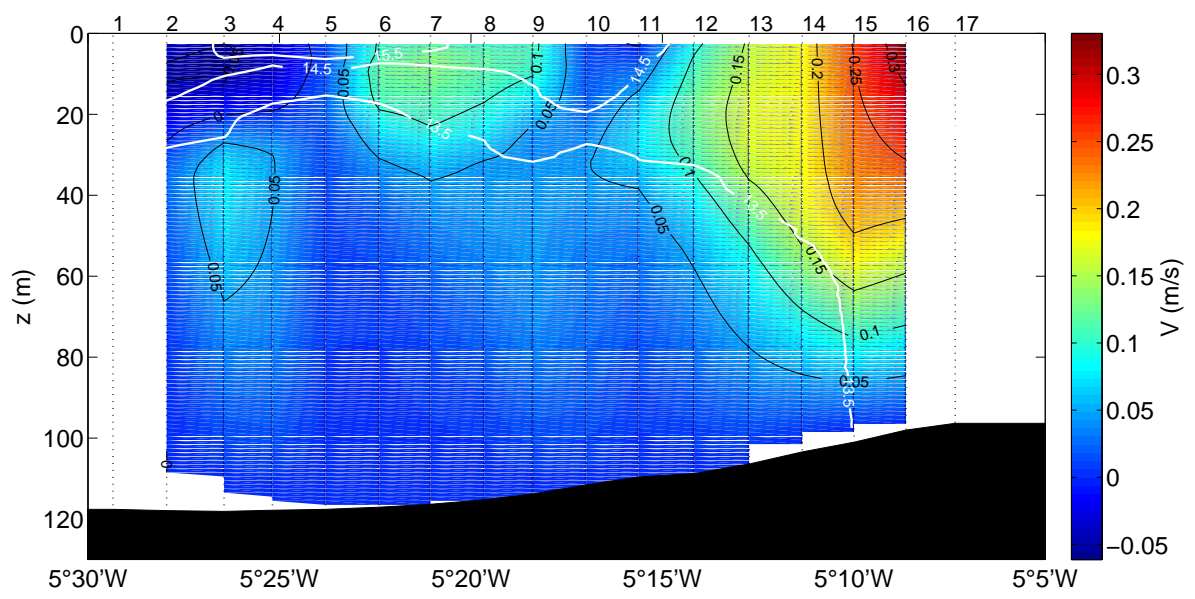

Figure 3: Northward geostrophic velocity across the $48^{\circ} 08^{\prime} \mathrm{N}$ transect, estimated assuming the density to depend on temperature alone, assuming a zero northward velocity at the sea-floor, and neglecting turbulent diffusivity effects. The thick white lines mark the $13.5,14.5$ and $15.5^{\circ} \mathrm{C}$ isotherms. 


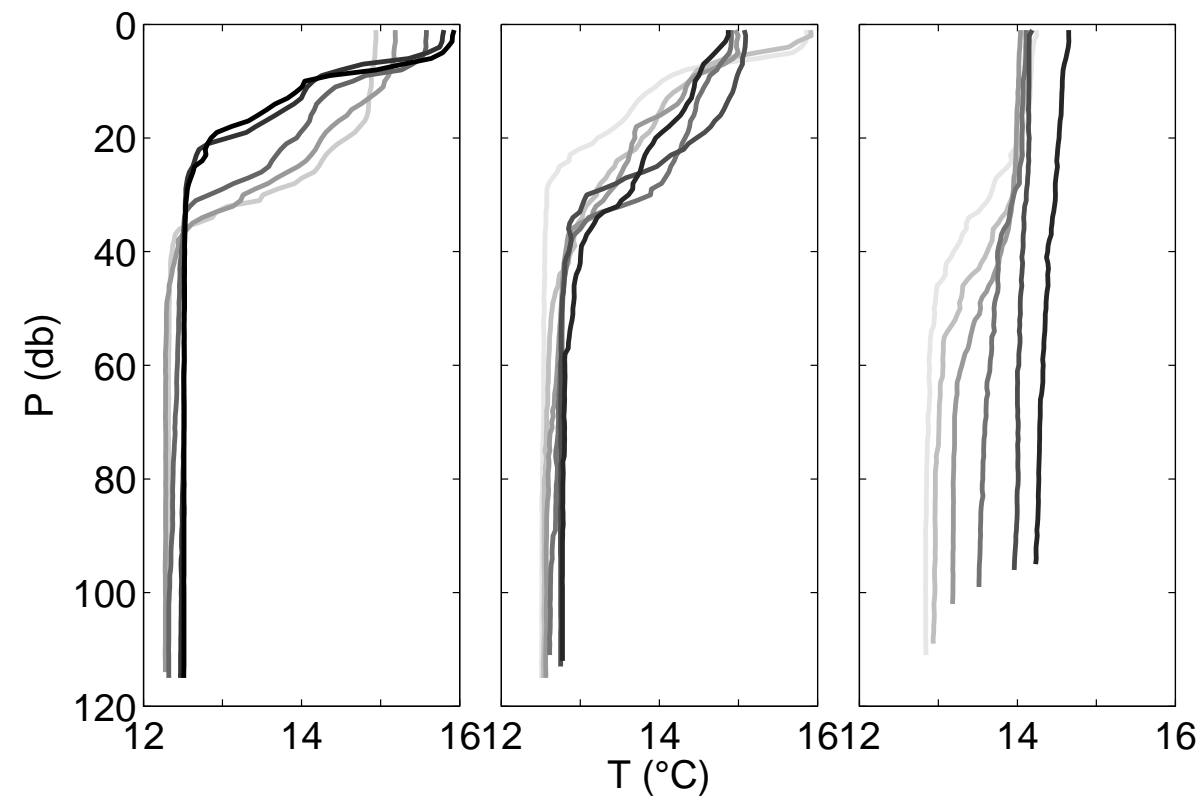

Figure 4: Temperature profiles for stations (a) 1 to 5 , (b) 6 to 11 , (c) 12 to 17 of the $48^{\circ} 08^{\prime} \mathrm{N}$ transect presented in figure 2 . In each graph, increasing station numbers are associated to darkening shades of grey (stations 1, 6 and 12 are lightest, stations 5, 11 and 17 are darkest). 

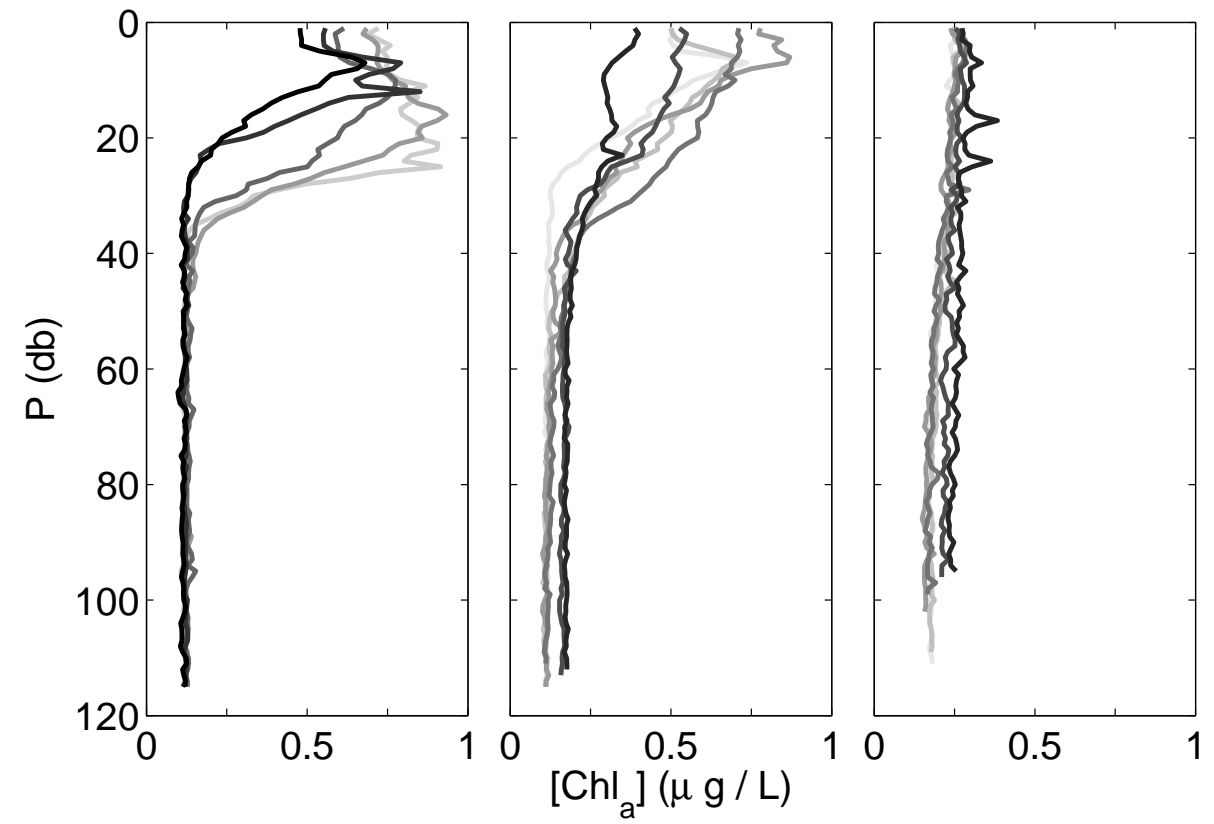

Figure 5: Raw (i.e. uncalibrated) chlorophyll-a concentration profiles for the same stations as figure 4. Same colour code. 


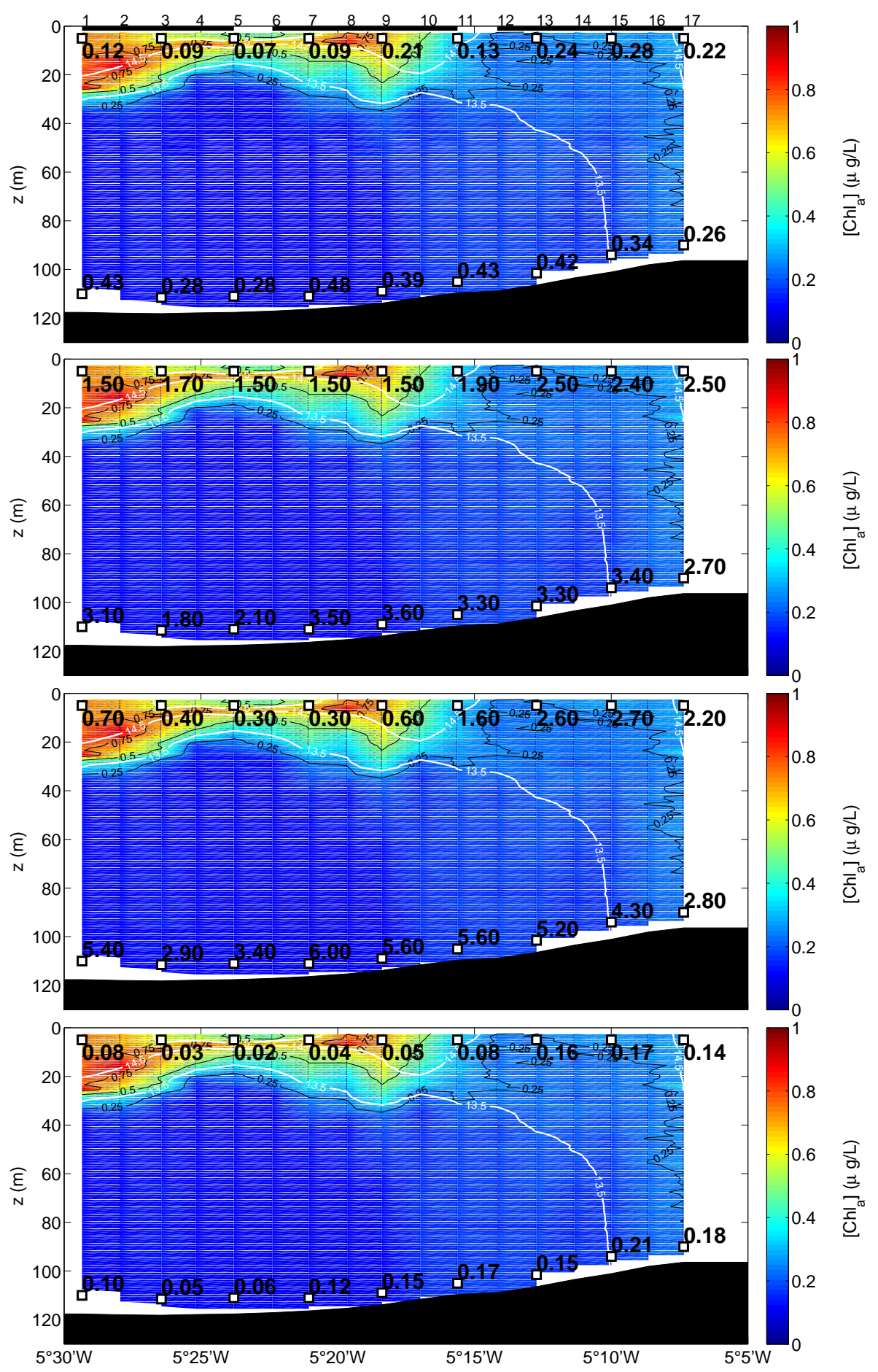

Figure 6: Surface and bottom nutrient concentrations (thick black figures) along the $48^{\circ} 08^{\prime} \mathrm{N}$ transect, superimposed on the raw chlorophyll-a concentrations. White squares mark the sampling positions. The thick white lines mark the $13.5^{\circ} \mathrm{C}, 14.5^{\circ} \mathrm{C}$ and $15.5^{\circ} \mathrm{C}$ isotherms. a) Phosphate concentrations $\left(\mu \mathrm{mol}_{1} \mathrm{l}^{-1}\right)$. b) Silicate concentrations $\left(\mu \mathrm{mol} . \mathrm{l}^{-1}\right)$. c) Nitrate concentrations $\left(\mu \mathrm{mol} . \mathrm{l}^{-1}\right)$. d) Nitrite concentrations $\left(\mu \mathrm{mol} .1^{-1}\right)$. The very low nutrient concentrations observed at the bottom of the water column at stations 3 and 5 are surprising, and are probably due to mishandling of the samples prior to analysis. These data will not be discussed in the text. 


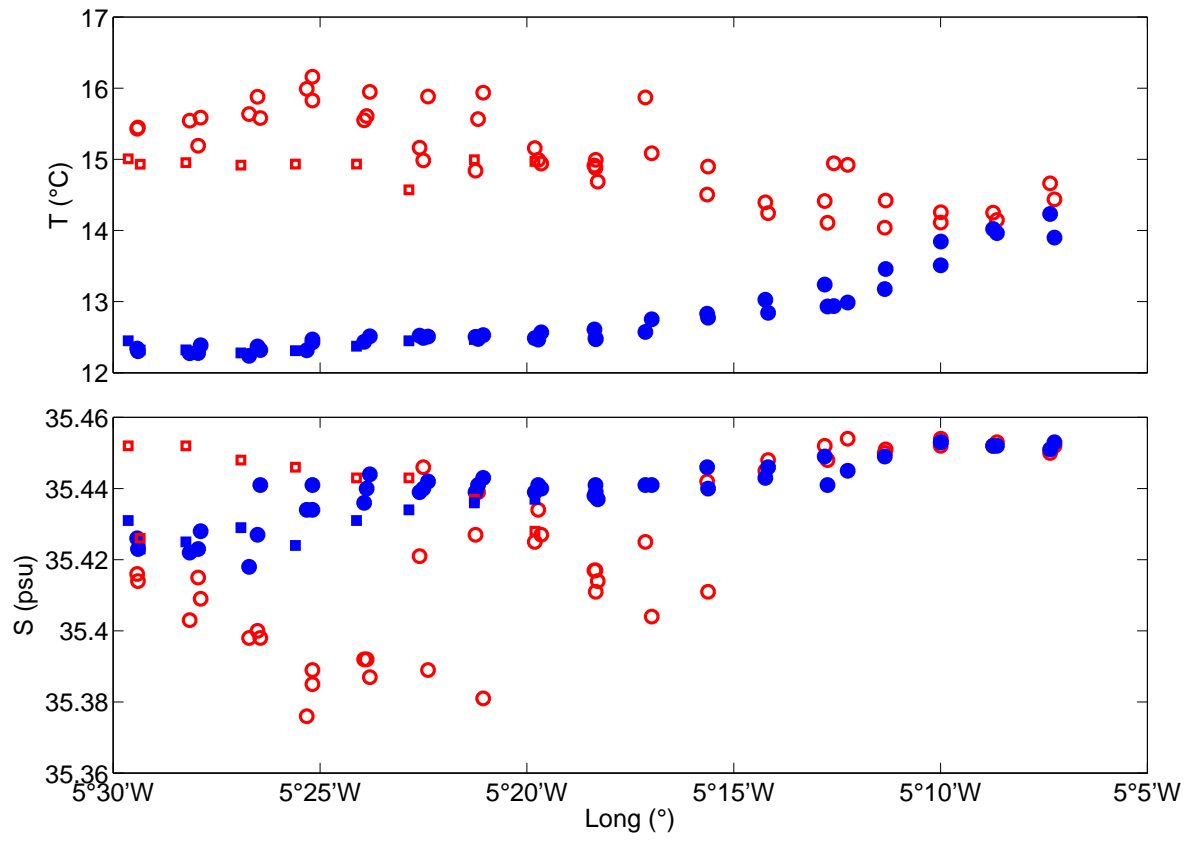

Figure 7: (a) Surface and bottom temperatures as functions of longitude. (b) Surface and bottom salinities as functions of longitude. Both plots use the data set of the four transects conducted during the first leg. In both graphs, the surface (resp. bottom) values are denoted by open (resp. full) symbols. In both graphs, the data from the second northern-most transect, which consistently stand out of the common pattern, have been marked with squares. This behaviour can probably be ascribed to a non-synopticity effect (see section 6). These data will not be discussed in the text. 

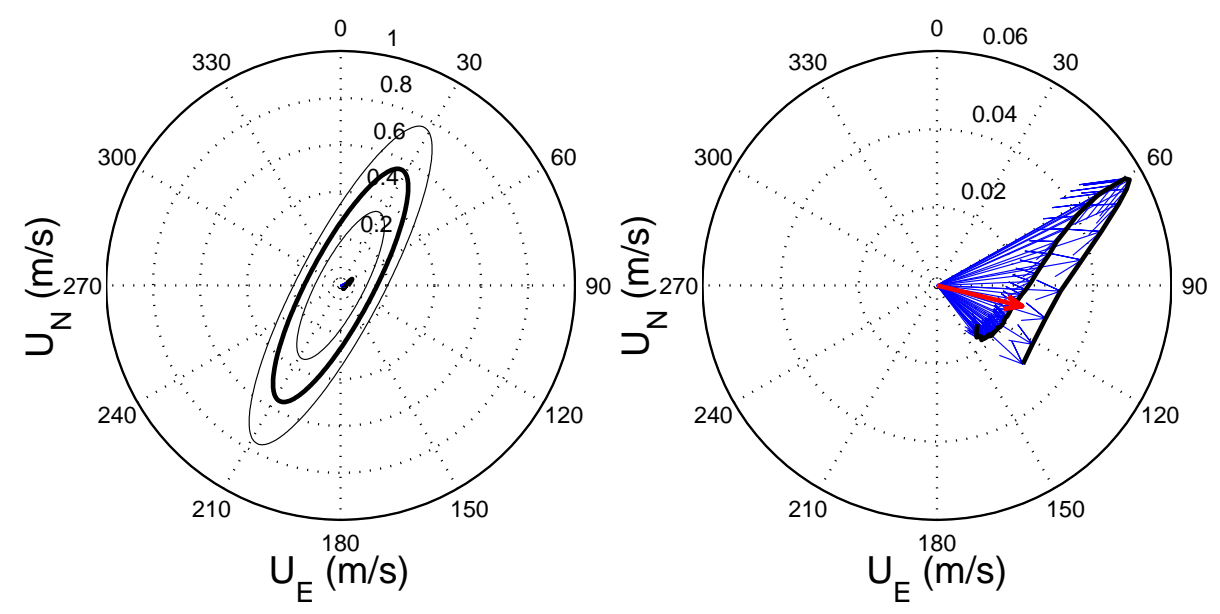

Figure 8: (a) Depth-averaged currents tidal ellipses over the mooring period. Thick black line: M2 tidal ellipse. Thin black lines: tidal ellipses at neap and spring tides. The time-averaged currents are also represented for comparison. (b) Time-averaged currents over the mooring period. One vector is represented for each $2 \mathrm{~m}$-high ADCP bin from 4 to $110 \mathrm{~m}$ above the sea floor. The thick black line joins the vector tips. A red arrow represents one hundredth of the time-averaged ECMWF analyzed wind over the area. 

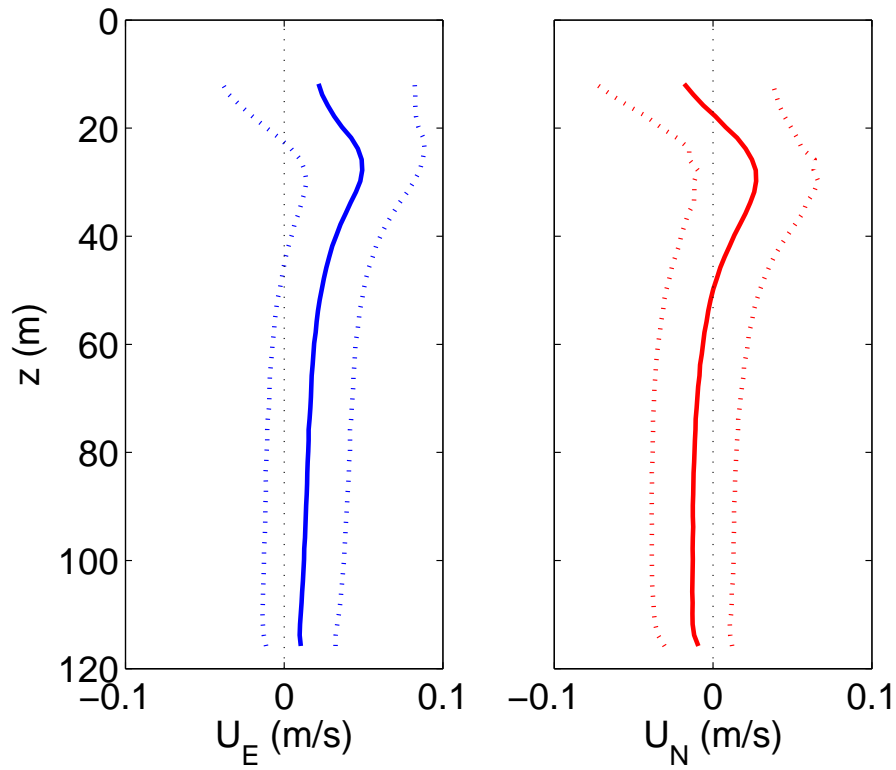

Figure 9: Profiles of the time-averaged current components as a function of depth. (a) Eastward component. (b) Northward component. On both graphs, the full line represents the time-average of the raw data, and the two dotted lines the time-average of the raw data plus/minus one rms amplitude. 

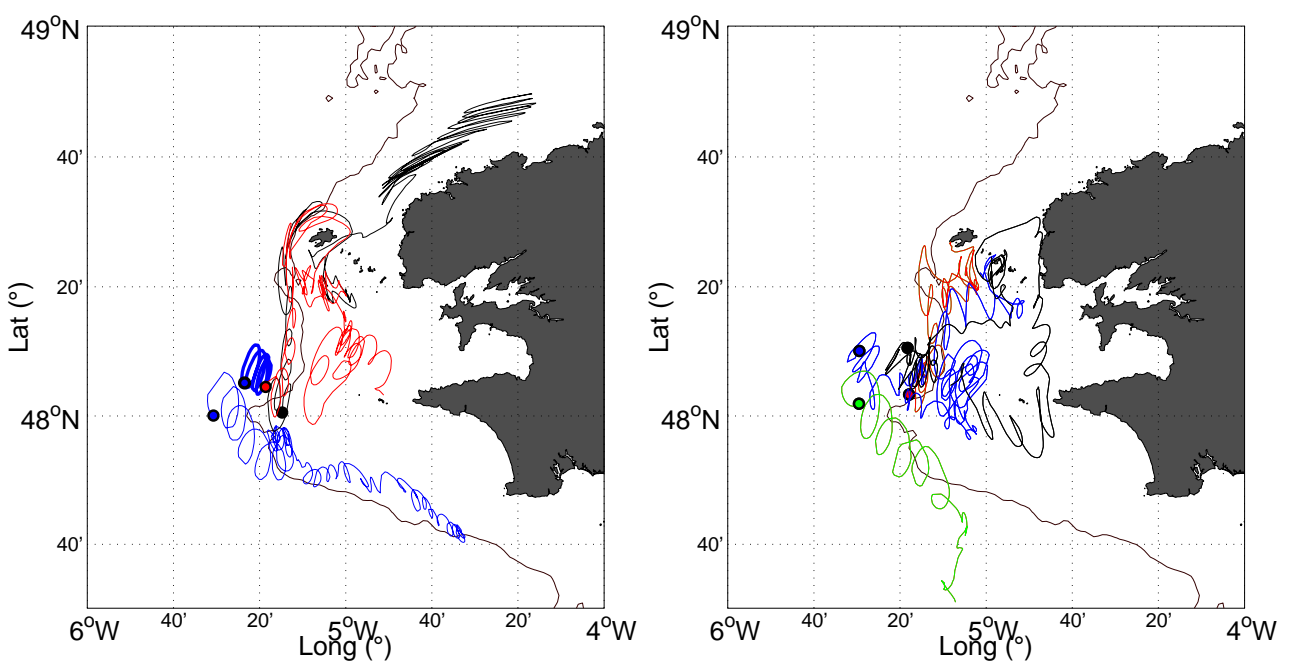

Figure 10: Trajectories of Lagrangian drifters over the period 09/13 $\rightarrow$ 09/30. Circles mark deployment points. (a) Thin (resp thick) lines: Holey-sock drogues at $15 \mathrm{~m}$ (resp. $50 \mathrm{~m}$ ). (b) CODE-type surface drogues. The $50 \mathrm{~m}$ holey-sock drogue drifter trajectory is limited to the $09 / 13 \rightarrow 09 / 15$ period. The group of islands at $48^{\circ} 25^{\prime} \mathrm{N}, 5^{\circ} \mathrm{W}$ constitutes the Ushant Archipelago. The "Raz de Sein" is the shallow sound at $48^{\circ} \mathrm{N}, 5^{\circ} 45^{\prime} \mathrm{W}$. 

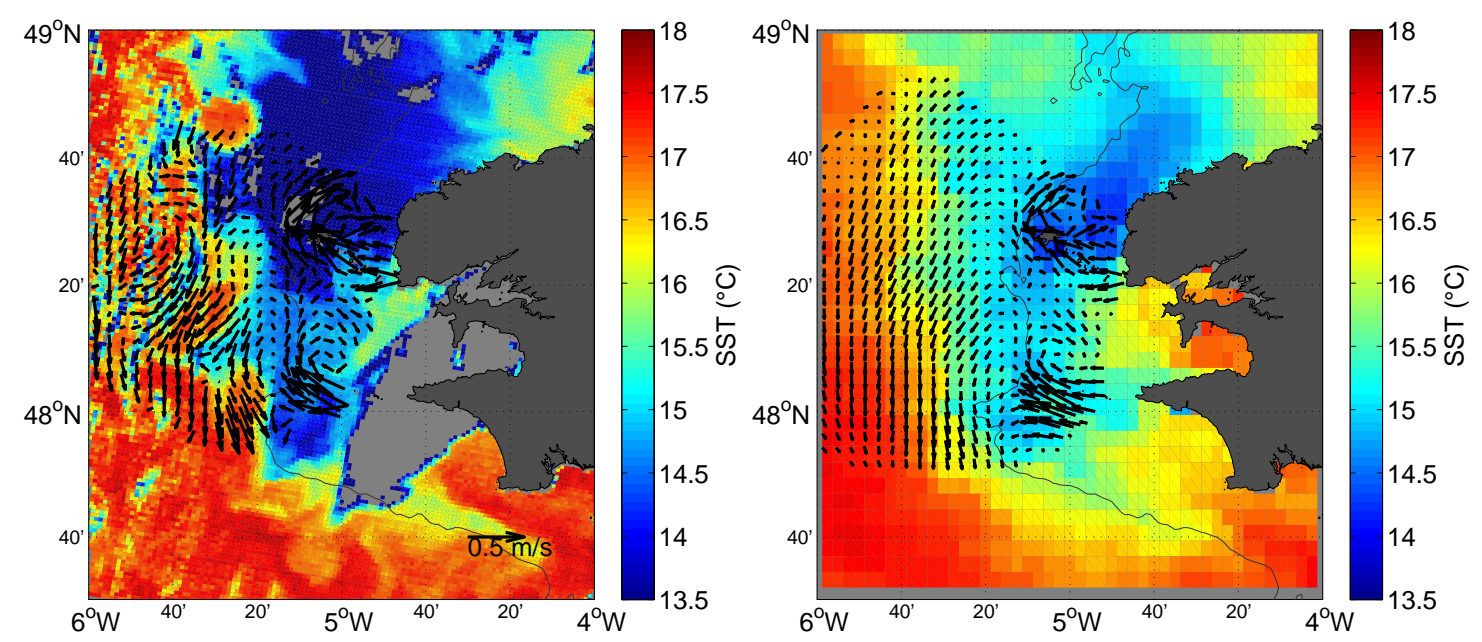

Figure 11: (a) Snapshot of the tide-filtered surface currents measured over the area by the HF radar system, on September 14th, 2007, at 02:20 UTC, superimposed on the SST map of September 14th, 02:20 UTC. (b) Surface currents measured by the HF radar system, averaged over the period 2007/08/15 $\rightarrow$ 2007/09/15, superimposed on the satellite SST composite map covering the the period 2007/08/13 $\rightarrow$ 2007/09/13 (Feldman and McClain, 2008). 

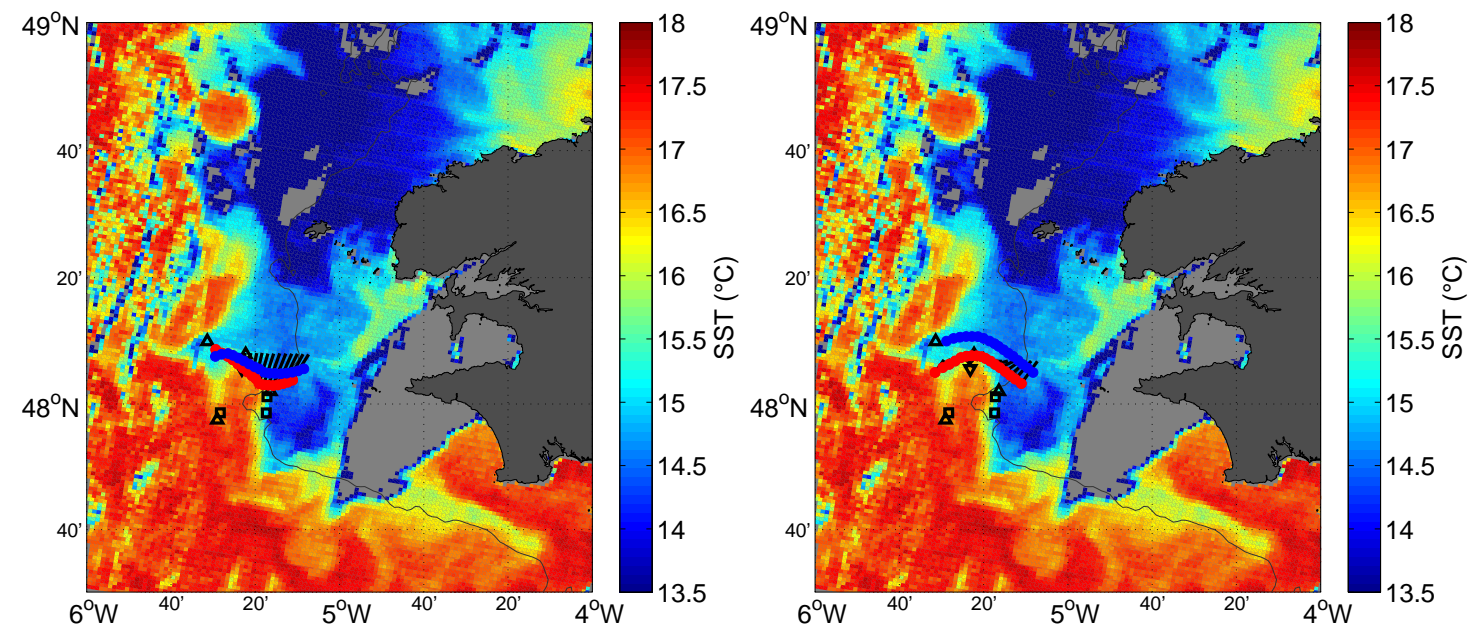

Figure 12: Positions at 02:20 UTC on September 14th 2007 of the water particles whose properties were measured during the $48^{\circ} 08^{\prime} \mathrm{N}$ (left) and $48^{\circ} 07^{\prime} \mathrm{N}$ (right) transects mentioned in the text. Red dots: estimated using the drifter trajectories. The marked drifter positions correspond to 02:20 UTC on September 14th 2007. Legend for drifter types as in figure 1. Blue dots: estimated using the spatial average of the HF radar surface currents over a 10' longitude by 10' latitude box centered on the ADCP mooring ( $\times$ in figure 1). 


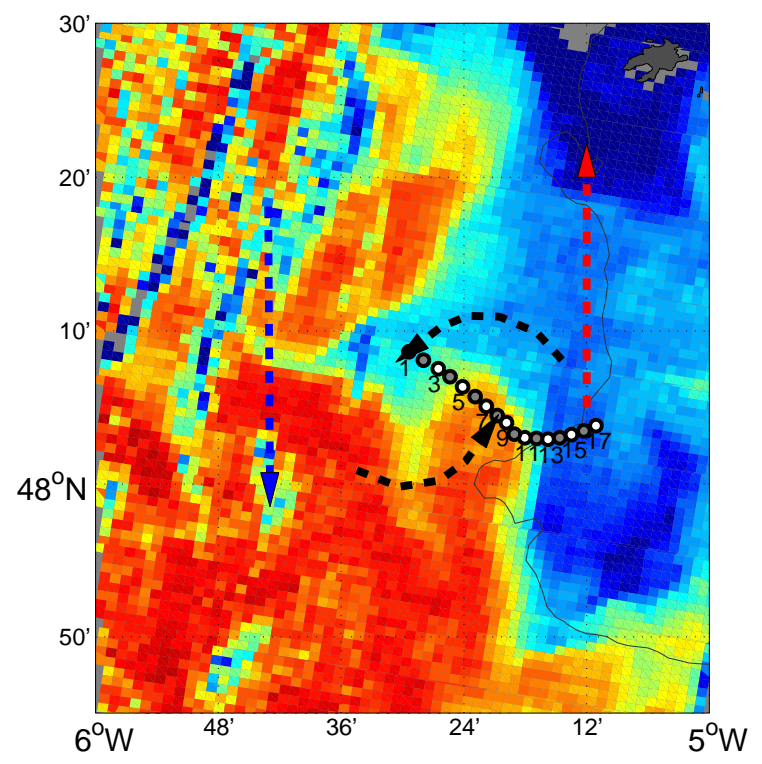

Figure 13: Tentative sketch of the surface circulation in the vicinity of the meander, superimposed on the SST map of September 14th 2007, 02:20 UTC. The red dashed arrow represents the northward jet associated to the bottom front. The blue dashed arrow represents the southward circulation associated to the bottom front. The two black dashed arrows indicate a plausible cyclonic structure, following (Pingree, 1978). The dots mark the position at the time of the SST picture of the water whose temperature was measured during the $48^{\circ} 08^{\prime} \mathrm{N}$ transect. Only odd station numbers have been marked for the sake of legibility. 

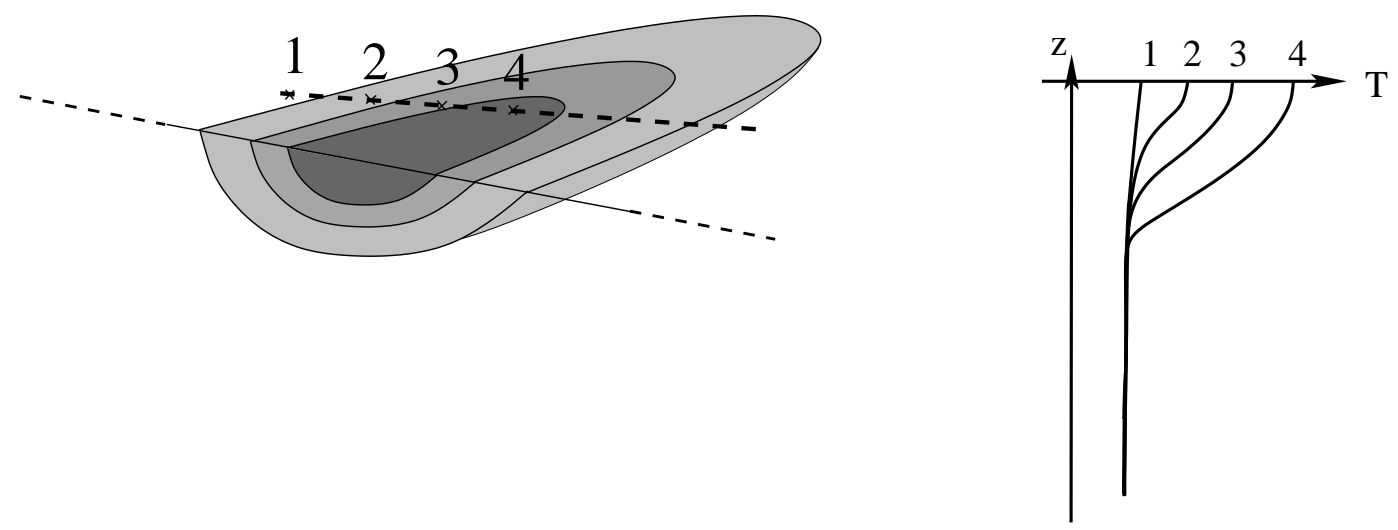

Figure 14: Sketch of an "adiabatic" warm-core frontal meander, and of the associated temperature profiles. 

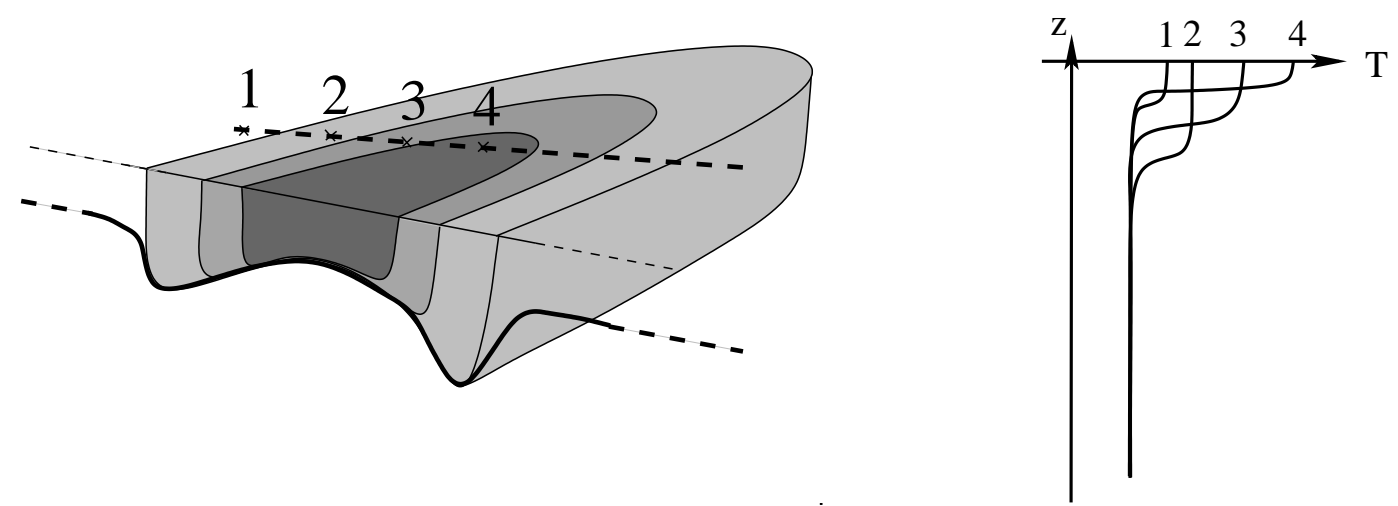

Figure 15: Sketch of a "diabatic" warm-core frontal meander, and of the associated temperature profiles. 

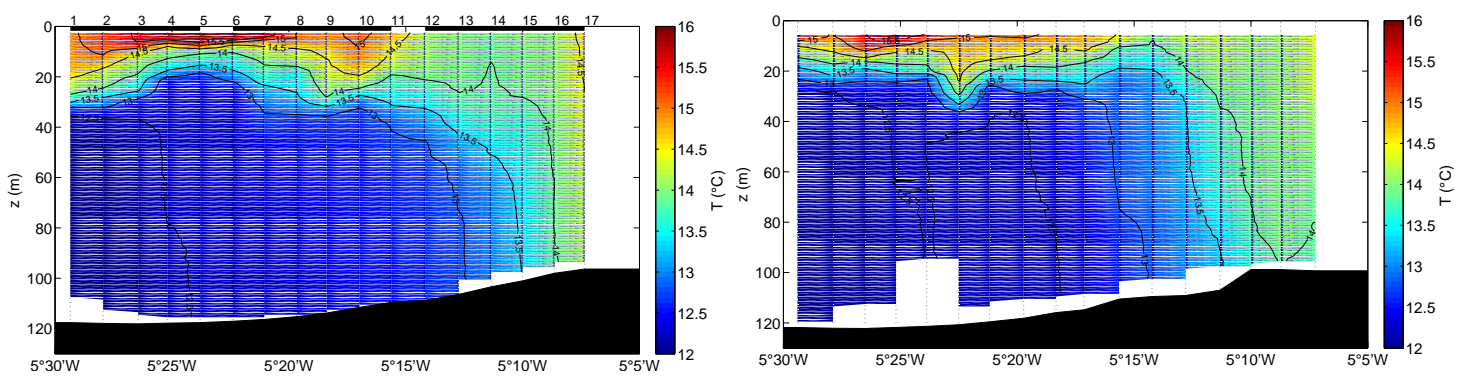

Figure 16: a) In-situ temperature section along the $48^{\circ} 08 \mathrm{~N}$ transect ( $c f$ figure 2 for legend). b) In-situ temperature section along the $48^{\circ} 07 \mathrm{~N}$ transect. This transect comprises 17 stations, marked on the graph as vertical dotted lines. The distance between station is of the order of one nautical mile. The survey started on 09/14, 08:25 UTC at the eastern-most station and ended on 15:30 UTC the same day. 


\section{References}

Aminot, A., Chaussepied, M., 1983. Manuel des analyses chimiques en milieu marin. Publications du CNEXO.

Broche, P., de Maistre, J.-C., Forget, P., 1983. Mesure par radar décamétrique cohérent des courants superficiels engendrés par le vent. Oceanologica Acta 6 (1), 43-53.

Brown, J., Carrillo, L., Fernand, L., Horsburgh, K., Hill, A., Young, E., Medler, K., 2003. Observations of the physical structure and seasonal jet-like circulation of the Celtic Sea and St. George's Channel of the Irish Sea. Continental Shelf Research 23 (6), 533-561.

Brown, J., Fernand, L., Horsburgh, K. J., Hill, A. E., Read, J. W., 2001. Paralytic shellfish poisoning on the east coast of the UK in relation to seasonal density-driven circulation. Journal of Plankton Research $23(1), 105-116$.

Cochin, V., 2006. Fourniture et qualification des mesures de courants de surface issues des radars HF. Tech. rep., Actimar, Brest.

Feldman, G. C., McClain, C. R., 2008. Ocean Color Web, MODIS Reprocessing. NASA Goddard Space Flight Center.

URL http: //oceancolor.gsfc.nasa.gov/

Garrett, C. J. R., Loder, J. W., 1981. Dynamical aspects of shallow sea fronts. Philosophical Transactions of the Royal Society of London A 302 (1472), 563-581.

Gurgel, K.-W., Antonischki, G., Essen, H.-H., Schlick, T., 1999a. Wellen radar (WERA): a new groundwave HF radar for ocean remote sensing. Coastal Engineering 37 (3), 219-234.

Gurgel, K.-W., Essen, H.-H., Kingsley, S. P., 1999b. High-frequency radars: physical limitations and recent developments. Coastal Engineering 37 (3), 201-218.

Hill, A. E., 1996. Spin-down and the dynamics of dense pool gyres in shallow seas. Journal of Marine Research 54 (3), 471-486.

Hill, A. E., Brown, J., Fernand, L., Holt, J., Horsburgh, K. J., Proctor, R., Raine, R., Turrell, W. R., 2008. Thermohaline circulation of shallow tidal seas. Geophysical Review Letters 35 (11), L11605.

Hill, A. E., James, I. D., Linden, P. F., Matthews, J. P., Simpson, J. H., Gmitrowicz, E. M., Smeed, D., Lwiza, K. M. M., Durazo, R., Fox, A. D., Bowers, D. G., 1993. Dynamics of tidal mixing fronts in the North Sea. Philosophical Transactions of the Royal Society of London A 343 (1669), 431-446.

Holligan, P. M., 1981. Biological implications of fronts on the northwest European continental shelf. Philosophical Transactions of the Royal Society of London A 302 (1472), 547-562. 
Horsburgh, K. H., Hill, A. E., Brown, J., Fernand, L., Garvine, R. W., Angelico, M. M. P., 2000. Seasonal evolution of the cold pool gyre in the western Irish Sea. Progress in Oceanography 46 (1), 1-58.

Houghton, R. W., 2002. Diapycnal flow through a tidal front: a dye tracer study on Georges Bank. Journal of Marine Systems 37 (1), 31-46.

Le Corre, P., Mariette, V., 1985. Le front thermique d'Ouessant en août et septembre 1982, Campagne SATIR - DYNATLANT. Vol. 1 of Campagnes Océanographiques Françaises. Institut Français de Recherche pour l'Exploitation de la Mer.

Le Fèvre, J., 1986. Aspects of the biology of frontal systems. Advances in Marine Biology 23, 163-299.

Le Fèvre, J., Grall, J. R., 1970. On the relationship of noctiluca swarming off the western coast of Brittany with hydrological features and plankton characteristics of the environment. Journal of Experimental Marine Biology and Ecology 4, 287-306.

Lueck, R. G., 1990. Thermal inertia of conductivity cells: Theory. Journal of Atmospheric and Oceanic Technology 7 (5), 741-755.

Lueck, R. G., Picklo, J., 1990. Thermal inertia of conductivity cells: Observations with a Sea-Bird cell. Journal of Atmospheric and Oceanic Technology 7 (5), 756-768.

Mariette, V., Le Cann, B., 1985. Simulation of the formation of Ushant thermal front. Continental Shelf Research 4 (6), 637-660.

Mariette, V., Rougier, G., Salomon, J. C., Simon, B., 1982. Courants de marée en Mer d'Iroise. Oceanologica Acta 5 (2), 149-159.

Morin, P., Le Corre, P., Le Fèvre, J., 1985. Assimilation and regeneration of nutrients off the West Coast of Brittany. Journal of the marine biological Association of the United Kingdom 65 (3), 677-695.

Morin, P., Wafar, M. W. M., Le Corre, P., 1993. Estimation of nitrate flux in a tidal front from satellitederived temperature data. Journal of Geophysical Research 98 (C3), 4689-4695.

Pawlowicz, R., Beardsley, B., Lentz, S., 2002. Classical tidal harmonic analysis including error estimates in MATLAB using t_tide. Computers and Geosciences 28 (8), 929-937.

Pingree, R. D., 1978. Cyclonic eddies and cross-frontal mixing. Journal of the Marine Biological Association of the United Kingdom 58 (4), 955-963.

Pingree, R. D., Holligan, P. M., Head, R. N., 1977. Survival of dinoflagellate blooms in the western English Channel. Nature 265, 266-269. 
Pingree, R. D., Mardell, G. T., 1987. Tidal flows around the Channel Islands. Journal of the Marine Biological Association of the United Kingdom 67 (4), 691-707.

Sharples, J., Moore, C. M., Rippeth, T. P., Holligan, P., Hydes, D. J., Fisher, N. R., H., S. J., 2001. Phytoplankton distribution and survival in the thermocline. Limnology and Oceanography 46 (3), 486496.

Simpson, J. H., 1981. The shelf-sea fronts: implications of their existence and behaviour. Philosophical Transactions of the Royal Society of London A 302 (1472), 531-543.

Simpson, J. H., Hunter, J. R., 1974. Fronts in the Irish Sea. Nature 250, 404-406.

Treguer, P., Le Corre, P., 1975. Manuel d'analyse des sels nutritifs dans l'eau de mer. Utilisation de l’Autoanalyzer II Technicon, 2nd ed. Université de Bretagne Occidentale, Brest. 